\title{
CONTRABANDO E BANDEIRISMO NO SEGUNDO QUARTEL DO SÉCULO XVII.
}

Apesar de vasculhados por inúmeros historiadores, existe ainda nos arquivos de Espanha (Madrí, Sevilha, Simancas) muita documentação inédita referente a São Paulo nos séculos XVI e XVII. Especialmente quanto ao período da dominação espanhola, abundam valiosos documentos que, conhecidos e publicados, viriam, não duvidamos, trazer novas luzes e dar ensejo a interpretações diferentes à documentação já publicada e perlustrada.

A história do bandeirismo paulista, por exemplo, poderia ser encarada por novos prismas, e ser reescrita com linhas mais fortes, dando à famosa epopéia, não apenas o interêsse do preamento do selvícola como fonte de renda de uma comunidade pobre, $e$ indiretamente o alargamento de nossas fronteiras, porém, mais do que isso, o escopo de, paulatinamente, alcançar o coração da conquista espanhola - o Perú - com os seus famosos veios de prata e o fabuloso comércio de contrabando.

Assim, há também um capítulo de nossa história que ainda não foi ventilado suficientemente - a história do contrabando no Prata em função dos portos brasileiros, história que se pode vislumirar de certos documentos, alguns já manuseados e publicados, como os que foram encontrados nos "juízos de residência", nas denúncias contra "oficiais reais", nos "autos de inquisição" e ocasionalmente contra "mercadores" e "mestres de navios" e outras pessoas interessados no tráfico.

Do exame dêsses documentos pode-se inferir uma como que ligação entre certos governadores do Prata e mesmo de altas autoridades, incluindo as eclesiásticas - como no caso do Bispo de Tucuman, que armou três expedições, duas das quais fracassaram com governadores e autoridades do Brasil (Bahia, Rio de Janeiro, Espírito Santo), que facilitavam o contrabando, ou o fomentavam em proveito próprio, através dos célebres "navios de aviso" a que se permitiam a entrada, e, bem assim, os que se diziam acossados por inimigos, por tempestades inexistentes, ou com avaria, ou falta de gêneros. Tudo pretexto para, sob a vista grossa dos responsáveis pela cousa pública, contrabandear mercadorias de todo o gênero. 
Também, ainda não se deu a devida extensão e importância à função da "via terrestre" nesse comércio de contrabando que, partindo de São Paulo, através do Paraguai, ia alcançar o Perú, em busca da prata de Potosi, principalmente da prata "não quintada", que se escoaria por essa via com duplo benefício - sonegação ao fisco e introdução de mercadorias contrabandeadas.

Não seriam as "bandeiras", principalmente depois de 1620 , também uma capa para o comércio ilícito ou, pelo menos, a proteção para certos indivíduos que pretendiam introduzir-se no Perú? Não se teria formado um grupo para exploração do comércio de contrabando "via terrestre", grupo êsse que provàvelmente fomentaria e financiaria certas "bandeiras"?

Não se pode negar, pelo menos, a existência, principalmente na Bahia, de um grupo poderoso (judeu ou não), que liderava o comércio de contrabando para o Prata, via marítima, do qual o português Diogo da Veiga (Diego de Vega, nos documentos espanhóis) seria um dos chefes, senão o principal.

E não é estranho que êsse Diogo da Veiga, acusado pelo governador Hernando Árias de Saavedra em 1616, de contrabandista poderoso, que burla acintosamente e sem receio as cédulas e ordenanças reais, por intermédio de Juan de Vergara, grande chicanista e conhecedor das leis, que torna legal o que é ilegal (1), venha a ser anos depois, em 1629, louvado pelo Padre Simon Maceta, da Companhia de Jesus, como "homem muito honrado, zeloso da honra de Deus e da salvação dos índios" que, sabendo da razia feita pelos bandeirantes nas reduções jesuíticas, se ofereceu para levá-lo, à sua própria custa a Espanha e a trazê-lo de volta a São Paulo e Buenos Aires, prontificando-se a gastar tôda a prata que fôsse necessária para "desterrar do Brasil tão injustos cativeiros e vendas e compras de índios"? (2).

Chefe poderoso dos contrabandistas "via maritima", não estaria com essas providências tentando destruir um grupo rival interessado no contrabando "via terrestre", de que certas "bandeiras" seriam o veículo e a "cortina de fumaça"?

Essas e muitas outras hipóteses, que poderão defluir de documentos já conhecidos em confrônto com documentação ainda por manusear, poderão, talvez, ser evidenciadas e demonstradas quando fôrem devidamente perquiridos os arquivos europeus, principalmente portuguêses e espanhóis .

Por ora, queremos levantar uma pontinha do véu e encarar a grande bandeira de 1629 de Raposo Tavares, à luz de um documen-

(1). - Antecedentes de Política Econômtica en el Rio de la Plata. I vol., pgss. 353-354.

(2). - Anais do Museu Paulisas. Tomo II, pg. 249. 
to inédito, assim o acreditamos, que recebemos do "arquivo de Indias" - a consulta do Conselho das Índias ao Rei em 29 de março de 1639, que daria como conseqüência a célebre cédula real de 16 de setembro de 1639 contra os paulistas.

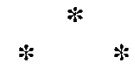

Dois acontecimentos marcantes, produzidos na mesma época, influenciariam de modo decisivo a história da Capitania de São Vicente no final do século XVI. Queremos nos referir à incorporação de Portugal à Côroa de Espanha e à segunda fundação de Buenos Aires, ambas no ano de 1580 .

Muito se tem escrito a respeito da reunião das duas corôas, sob um único cetro, mas, sob o ângulo que queremos ressaltar, não resta dúvida que a política administrativa, "um tanto vesge", dos Habsburgos foi favorável à expansão portuguêsa além dos limites impostos pelo tratado de Tordesilhas. Se a corôa espanhola, desde o princípio - e atendo-se aliás à sua velha diretriz de que só os castelhanos dentro de seu vasto império tinham direito aos "negócios" de América - tivesse considerado o perigo da infiltração portuguêsa e defendido suas posições chaves, possìvelmente o bandeirismo de apressmento, com tôdas as suas conseqüências políticas, econômicas e sociais não teria eclodido com a pujança e o destemor que o caracterizou.

Mas, o êrro maior da política espanhola, a nosso ver, mais que irresponsabilidade na defesa territorial, se vai verificar no setor econômico da política platina, em face da segunda fundação de Buenos Aires.

Realmente, o pôrto de Buenos Aires, não fôsse a irredutibilidade da política comercial da metrópole - monopólio sevilhano, portos privilegiados na América, fechamento do Rio da Prata deveria desempenhar normalmente um papel de grande destaque, como escoadouro da produção dos centros interiores do Paraguai, Tucuman e Potosi. Por êle poderia circular um importante comércio de gêneros, manufaturas e negros e assim estimul-ir as fontes de produção, que funcionariam em sincronismo com a prata peruana.

Porém, mui poderosos eram os interêsses do comércio sevilhano e estreita e estrábica a política comercial de Espanha, para permitir qualquer restrição aos lucros decorrentes do mercado importantíssimo, que era o peruano.

Assim, não restou a Buenos Aires outra alternativa senão voltar-se em direção ao Brasil, principalmente para a região sulina que, por razóes óbvias, tinha os olhos voltados para o Prata. 
Da existência de um comércio entre o Brasil e Buenos Aires, por vêzes legal, ilegal quase sempre, em princípios do século XVII, não há negar-se. Havia a justificá-lo, além das aperturas econômicas da região platina, os interêsses de autoridades administrativas (Zárate), o zêlo de outras (Hernandárias) e as prementes necessidades dos colonos.

De que, por vêzes, foi permitido e legal o comércio entre Buenos Aires e Brasil, a par do contrabando de passageiros e de prata, vamos encontrar a prova na carta de Hernandárias de Saavedra a Sua Maje tade em 5 de abril de 1604 (3). Depois de se referir à cédula de "permissão" de se embarcarem para o Brasil "farinhas das colheitas e frutos da terra (Buenos Aires)", salienta que proibiu a entrada de farinhas provenientes de Córdoba, porque com elas se trazia "prata e passageiros" que passavam ao Brasil ocultamente. Logo após, dá conta de ter permitido licença a apenas 8 navios, cujos mestres e donos deram fiança de não embarcarem passageiros ou coisas proibidas, de acôrdo com as ordens de Sua Majestade. Não obstante, høvendo recebido denúncia, fêz visita a cinco navios que deviam partir, encontrando três passageiros vindos do Perú com 25.000 pesos em prata e alguma quantidade de farinha embarcada sem licença.

E que isto deveria ser corrente e comum, com a cumplicidade das autoridades, se verifica no desabafo de Hernandárias, na mesma carta, em que afirma que anteriormente tinham passado em outros dois ou três navios "certos passageiros delinqüentes do $\mathrm{Pe}-$ rú", que não teriam passado se "vossos oficiais tivessem feito as visitas como deviam", e não de acôrdo com "seus interêsses, pouca pontualidade e remissão".

Mas, o comércio legal foi exceção e só para atender à grita dos colonos, quando havia em demasia, sem escoamento, farinha, sebos e couros.

Do lado do Brasil, estamos quase certos, deveria existir no Rio de Janeiro, em princípios do século XVII, um núcleo instável de comerciantes judeus que vivia do comércio com o Prata. Evidência disso será a afluência de portuguêses em Buenos Aires, em 1609 , apenas com a notícia da visitação do "Santo Ofício" ao Rio de Janeiro (4).

Mas, além do pôrto do Rio de Janeiro, a atração do mercado peruano influenciaria também o planalto de Piratininga que, por "via terrestre", embora difícil e acidentada, porém não impossivel, participou dêsse comércio ilícito. Tanto a "via terrestre" co-

(3). - Anais do Museu Paulista. Tomo I. pgs, 270-284.

(4). - Medina, J. T., La Inquisicion en el Rio de La Plata. Buenos Aires, 1945. 
mo a "via marítima" eram proibidas, mas ambas foram igualmente trilhadas.

E a acoroçoar êsse comércio ilícito estava a administração espanhola, com suas limitações e proibições, em tudo que pudesse afetar as concessões ao comércio de Lima. Até mesmo o fornecimento de escravos negros autorizado com os primeiros "asientos" foi suspenso, sob a alegação de que com êles entravam também mercadorias de contrabando.

Como reação à atitude da Metrópole, atirou-se Buenos Aires desenfreadamente ao contrabando. E cresceu de tal forma que, segundo Molina (5), já em princípios do século XVII era impossível extirpá-lo. De tal arte se houveram os contrabandistas que chegaram a constituir sociedades, como a de Diogo da Veiga, Simão Valdez e Juan de Vergara. Estes, sob as vistas "complacentes" dos oficiais reais, chegariam a criar o "contrabalndo exemplar", forma idealizada para fraudar os cofres reais, com um mínimo de riscos.

Assim, a "via marítima" do contrabando crescia e tomava importância, enquanto a "via terrestre", cujo ponto de partida natural era o planalto piratiningano, era menos concorrida e trilhada.

Talvez viesse a ser a rota preferida - quem sabe - para o transporte oficial da prata, como despistamento, durante o período da unificação peninsular, em face da presença de piratas e corsários, cada vez mais audaciosos, nas rotas normais do século XVII. Saavedra chegou até fazer sondagens, em 1603, sôbre as possibilidades dêsse caminho. Mas, se planos nesse sentido existiram, êles foram derrubados pelos planaltinos, que escolheram essa via para suas incursões contra as reduções jesuíticas, em busca de "mão de obra" escrava.

Mas, a valorização dessa "via terrestre" vai se dar na terceira década do século XVII e por intermédio de uma figura que, a nosso ver, foi pouco estudada. Queremos nos referir a Don Luís de Céspedes Xéria, designado governador da província do Paraguai em 1625 .

$\mathrm{Na}$ verdade, a posição de $\mathrm{D}$. Luís de Céspedes Xéria ainda não foi bem ressaltada. Nomeado em fevereiro de 1625 só toma posse do cargo em 1628. Nesse interregno, passa por várias experiências, sediando-se por longo tempo em Lisboa, Bahia e Rio de Janeiro.

Inteligente, audaz e pobre dirigiu-se à América, para "fazer América". Não seria o primeiro caso. E não seria o último. Basta lembrar Don Diego de Góngora, nomeado em 1619 para o govêr-

(5). - Molina, Raul, Hernandarias, el hijo de la tierra. Buenos Aires, 1948. 
no de Buenos Aires, que já partira com o propósito firme de roubar o fisco quanto pudesse. Basta dizer que, antes de sair de Espanha, havia embarcado como contrabando, em quatro navios, mercadorias no valor de 300.000 cruzados (6).

Xéria, por motivos vários, um dos quais a procura de dinheiro, demorcu-se um ano em Lisboa, vinte meses na Bahia, quatro meses no Rio de Janeiro e um mês na capitania de São Vicente.

Se soubermos, como sabemos, que Lisboa era a Meca dos contrabandistas e que, na Bahia, se prolongavam os interêsses comerciais portuguêses, poderemos inferir que Xéria teria amadurecido, nesses lugares, planos porventura trazidos de Espanha, sôbre as possibilidades que oferecia o contrabando para o Perú, o que, talvez, os sucessos posteriores explicariam.

Deixando de lado as acusações dos jesuítas a D. Luís de Céspedes Xéria (7) de ter o mesmo entrado no Paraguai pela via proibida de São Paulo, trazendo consigo muita gente forasteira, eclesiástica e secular, que se dirigiram para os reino do Perú com sua ordem; que, à sua sombra veio uma armada de soldados da Vila de São Paulo com o pacto de que, da prêsa que fizessem em Gúzirá, fôssem enviados ao seu engenho no Rio de Janeiro cem varões indios e outras tantas mulheres; que, em dois anos de govêrno faciiitou por duas vêzes a vinda de portuguêses de São Paulo que, além de carregarem mais de 20.000 indios, cometeram grandes crueldades contra êles, a ponto de, pelos caminhos que vão a São Paulo, matarem os velhos e velhas que se cansam e os que adoecem, dando seus corpos aos cães para que os comessem; a verdade é que, sôbre ser pelo menos "curiosa" sua decisão de percorret a "via terrestre" para chegar à sua governação, contrariando ordens reais, e fazer mais tarde sua espôsa e sogra precorreram o mesmo caminho, apesar de tôdas as dificuldades, deve-se ainda suspeitar das precauções que tomou a cada passo para evitar um eventual "juízo de residência".

Realmente, Xéria, acusando falta de monção favorável para a navegação, requer em 1628 , ao capitão-mor de Santos que, tendo sido informado que algumas pessoas desejam ir ao Paraguai pela "via terrestre", que isso seja proibido sob grandes penalidades, por ser em prejuízo da Corôa de Castela, salvo as pessoas que fôrem mandadas para lhe acompanhar, sob pagamento (8). O curioso é que, em resposta, o capitão-mor de Santos, atendendo ao requerido, notifica os moradores da Vila de São Paulo, probindo-os de ir ao "Sertão" dar guerra aos índios sob pena de confisco de

(6). - Histótia de la Nación Atgentina. Vol. III, pg. 319.

(7). - Artais do Museu Paulista. Tomo III, pg. 265 e seguintes.

(8). - Anais do Museu Paulista. Tomo I, Pg. 175. 
suas fazendas, e dá licença ao Capitão Manuel Preto, para, com mais seis índios sòmente, sem levar em sua companhia mais nenhuma pessoa branca, acompanhar o Governador Xéria pelo rio abaixo em canoas, sem sair fora do caminho.

E quem era Manuel Preto? Apenas o capitão de tôdas as "malocas", vale dizer o chefe superior das "bandeiras" que se organizavam para o apresamento, e portanto supervisor da "bandeira" que seguiria suas pegadas em 1629, chefiada por Raposo Tavares.

Mas, continnuando a mesma ordem de idéias expressa atrás, repetimos, é de se suspeitar, pelo menos, as precauções minuciosas tomadas por Xéria, e que outra coisa não foram senão um despistamento, uma velatura para seus atos ocultos. Assim, requer primeiro ao ouvidor Amador Bueno, com alçada na Capitania de São Vicente, que proiba a passagem de pessoas para Assunção pela "via terrestre" que vai percorrer, e pede que mande dar um testemunho para que, em qualquer tempo, conste a Sua Majestade, que passou pelo caminho sem exceder as ordens reais; requereu e pediu que dito requerimento fôsse certificado pelo Tabelião Público Francisco Nuñez Cubas do seu deferimento favorável; fêz com que sua letra e firma, bem como as letras e firmas do ouvidor Amador Buenos e do Tabelião Francisco Nuñez Cubas fôssem certificados por outro Tabelião, Simão Borges; requereu ao Capitão-mor de Santos, que deu licença a Manuel Preto para acompanhá-lo, como vimos atrás; faz certificar por tabelião, o reconhecimento de sua letra e firma no requerimento, assim como o despacho favorável do Capitão-mor. Não contente, faz certificar pelos Padres da Companhia de Jesus do Colégio de São Paulo que não levou consigo mais que criados e roupa de seu uso, sem mais nada, mostrando-se outrossim mui zeloso do serviço de Sua Majestade. E não é só. Ao chegar em Guairá ordena aos oficiais reais que registrem a sua bagagem, para que se verifique que não leva mercadorias proibidas e manda extrair certidão da inspeção (9).

Tudo isso, para nós, não passava de "cortida de fumaça" para esconder as suas verdadeiras intenções.

Tudo nos leva a crer, ao contrário, que, em contacto com comerciantes e contrabandistas em Lisboa e na Bahia, tenha formado planos, que foram favorecidos por sua passagem no Rio de Janeiro, entrozando-se com os "Correia de Sá", expoentes no govêrno, na sociedade e nas finanças, chegando a esposar a filha de um dêles. Em São Paulo foi o toque final. As combinações chegaram ao seu têrmo, fechando o círculo.

(9). - Anais do Museu Paulista. Tomo I, pg. 172 e segs. 
Dêste modo, temos como indiscutível, em face da documentação existente, sobretudo a de origem jesuítica, que, pactuados e mancomunados, Manuel Preto - o chefe de tôdas as malocas (10) - e Don Luís Céspedes Xéria partiram, em agôsto de 1628, em demanda de Assunção, pela "via terrestre", proibida por "ordens reais", o primeiro aparentemente como guia, na verdade, porém, abrindo caminho para o grosso da bandeira de Raposo Tavares. Chegam, Xéria e Manuel Preto, à ribeira do rio da Cidade de Guairá, onde Preto se despede e fica, a 18 de setembro de 1628 'e, por essa mesma época, a bandeira de Raposo Tavares já havia atravessado o "Rio de Tibajiua", segundo representação dos padres Maceț l e Mancilla em outubro de 1629 ao Governador Geral da Bahia, Diego Luís de Oliveira (11).

Nesta bandeira, a maior que se organizara até então em São Paulo, pois só ficaram os velhos, "que por su vejez no podian yr", e 25 homens em condições de tomar armas, partiram novecentos pcrtuguêsez, com dois mil e duzentos índios aguerridos, e acompanhados de juízes e vereadores de São Paulo, assim como do juiz e do capitão de Santa Ana do Parnaiba, do procurador do Conselho de São Paulo e... do filho, genro e irmãos do ouvidor Amador Bueno, precisamente a quem $D$. Luís de Céspedes Xéria, nas vésperas da partida da bandeira, representa pedindo que notificasse e proibisse a passagem de pessoas que, segundo êle, desejavam "ir ao dito seu govêrno", de acôrdo com informações que diz ter recebido.

Por ordem do ouvidor Amador Bueno éditos são baixados proibindo a passagem de qualquer pessoa da Capitania para os territórics sob govêrno de Xéria, sob pena da multa de quinhentos ducados, e dias depois, nas pegadas de Xéria, move-se a vila inteira de São Paulo, incluindo autoridades e parentes da maior autoridade da Capitania...

Dessa bandeira foi declarado por Capitão-mor da primeira Companhia Antônio Raposo Tavares, e das outras Companhias os Capitães Pedroso de Barros, Blaz Leme e André Fernandes. E, como Mestre de Campo de tôdas estas Companhias, foi Manuel Preto, "autor de tôdas estas malocas"... (12).

Não vamos aqui, naturalmente, rememorar fatos já conhecidos da chamada "grande bandeira" de 1629. Basta citar que foram desmanteladas quatro reduções - "Encarnacion", "S. Pablo", "Los Angeles" e "S. Thomas Apostol" - e, segundo o documento que ci-

(10). - Maloca, do araucano: "Invasion en tierra de indios, con pillaje y exterminio" In Dicionário da Real Academia Espanhola.

(11). - Anais do Museu Pisulista. Tomo I, pgs. 247 e segs.

(12). - Anais do Museu Paulista. Tomo I, pgs. 247-257. 
tamos (13), "han arruinado no solo las reduciones", como fizeram despovoar três cidades espanholas, "Guayrá", "Xerez", Villa Rica". $\mathrm{E}$ teriam os bandeirantes usado de tanto rigor que, de trezentas mil almas "que an sacado del Paraguay no an llegado 20 mil al Brazil". E, continua o documento, com os ataques de outras bandeiras que se seguiram, acabaram-se totalmente "catorze reduciones del Paraguay, quedado solas dos porq. sus moradores se bajaron huyendo por el Rio Paraná".

Queremos apenas ressaltar, para fixar bem a responsabilidade de Xéria nessas bandeiras, que continuam por tôda a quarta década do século XVII, destruindo e provocando o recúo das reduções, de que resultaria a base para as futuras reivindicações territoriais, de Portugal, que êle nada fêz para impedir o passo dos bandeirantes, antes, pelo contrário, todos os seus ^ltos são no sentido de facilitação dessa tarefa.

Assim, sua mulher, Da. Vitória de Sá, com quem casara no Rio de Janeiro, sobrinha do governador Martim de Sá, ao se dirigir ao encôntro de seu marido no Paraguai, em 1631, escolhe exatamente a "via terrestre", mais difícil e penosa. Por que? Falta de "monção favorável" outra vez? Será por casualidade que a acompanham seu primo, o notável Salvador Correia de Sá e Benevides, o futuro "herói de três continentes", que se fixa no Paraguai a pedido de Xéria, e o não menos célebre capitão André Fernandes, "famoso conssario del serton", segundo Hernandárias, êsse André Fernandes que foi um dos capitães da bandeira de 1629? Seria ainda por casualidade que, nas pegadas de $\mathrm{Da}$. Vitória de Sá e à sua sombra, seguiu outra "Armada de Portuguêses", que rouba e destrói três reduções? Por acaso será que Xéria conserva aberto - "Caminho de São Paulo". enviando por êle despachos com espanhóis e muitos índios, que aí se quedam, sendo que muitos dêles no engenho que nossui no Rio de Taneiro? (14).

Não. Tudo indica um plano pré-estabelecido. As reduções são taladas e destruídas, com o seu beneplácito, donde the deveria provir fartos lucros, não tomando quaisquer providências, enquanto se levanta uma onda de clamor contra a gente de Piratininga, chegando algumas autoridades espanholas como o Conde de Chinchon - vice-rei do Perú - até a alvitrar o itrrasamento da Vila de São Paulo, como único remédio para quebrantar a audácia e a altivez dos paulistas...

Do documento que citamos no princípio dêste trabalho há, ainda muitas ilações a tirar.

(13). Consulta do Conselho de Indias a Sua Magestade em 1639.

(14). - Anais do Museu Paulista. Tomo II, Pgs. 266 e 269. 
Do seu exame poderemos inferir a situação da vida de São Paulo, em 1641, nas vésperas do reconhecimento de D. João IV, como rei de Portugal.

De fato, o documento em questão, depois de acentuar os crimes cometidos pelos paulistas contra as reduções jesuíticas, assinalando com côres vivas os prejuízos de tôda sorte causados a Espanha, comina penas severíssimas, de tal formal que difìcilmente haveria quem a elas escapasse.

Depois de proibir aos portuguêses a ida às reduções remanescentes, a não ser em condições especialissimas e, mais que isso, que, sob pena de morte ultrapassem a linha demarcatória das Tordesilhas, intima aos que porventura tenham notícias de novos delitos incursões às reduções - que notifiquem às autoridades do Rio de Janeiro ou de São Paulo, que devem desde logo prender os culpados, sequiestrar-lhes os bens, e entregá-los ao Santo Ofício, assim como devem ser punidas as autoridades que por desleixo ou omissão deixem de tomar as adeqüadas providências.

E; quanto aos delitos do passado, para que não fiquem sem punição, os governadores da Bahia e do Rio de Janeiro deviam proceder contra todos que acharem culpados de tais jornadas (bandeiras), principalmente os capitães e cabeças, especialmente Antônio Raposo Tavares e Frederico de Melo, que nas denúncias são os mais culpados. Êstes devem ser sacados dil terra e enviados presos, assim como diversos padres que participaram das "entradas". Também devem sair do Brasil os portuguêses e espanhóis que tenham sido "vizinhos" no Paraguai, pois que êsses podem servir de guias aos que desejarem formar novas "entradas". Em particular Sebastião Peralta, Diego Guillermo, Don Diego Dorrego, Fulano Ponce, Francisco Sanchez e outros, que devem ser presos e remetidos ao Conselho de Indias.

Assim também, todos aquêles que houvessem comprado indios provindos das reduções deveriam exibí-los e devolvê-los, sob pena de costigos severos, e bem assim todos os que levassem ou conduzissem tais índios, de um lugar para outro, para efeito de dá-los, alugá-los ou vendê-los.

Dêste modo, em São Paulo de Piratininga, raros seriam os que poderiam escapar às cominações recomendadas ao Rei. Capitães, chefes, clérigos, possuidores de índios, meros transportadores, todos incidiam nas sanções.

E assim, em 1641, à notícia da separação de Portugal da Espanha e ascensão de D. João IV ao trono houve, por assim dizer, um alivio geral. 
Ocorreu então, por parte de alguns, a aclamação de Amador Bueno, que recusa firme e prontamente a honraria, dando vivas a D. João IV.

Explosão nativista? Não temos essa impressão. Pensamos, entretanto, no grupo espanhol existente, possivelmente de espanhóis aqui radicados, provenientes das cidades espanholas desaparecidas em função da destruição das reduções e que segundo o documento, se teriam unido aos portuguêses e se locupletado com 0 comércio de índios e estariam temerosos de punição. A justificar essa idéia, lembramos ainda o documento em que são citados nominalmente diversos espanhóis, residentes no Planalto, que deviam ser remetidos presos para a Espanha.

Assim, possìvelmente, êsse grupo, aliado a alguns idealistas, teria preferido se bater por um rei local do que aclamar o Duque Bragantino, mormente que, ainda a se admitir a existência de um sentimento de independência, a maioria dos planaltinos estaria fora, ocupada que estava nos sertões do M'Bororé.

De uma forma ou de outra, queremos evidenciar que, em razão da cédula de 1639, também os habitantes de Piratininga tinham interêsses numa ou noutra fórmula, contanto que ficassem subbtraídos às sanções e castigos. Tanto que Raposo Tavares, após haver aclamado Amador Bueno, apressa-se logo a se juntar aos que reconheceram D. João IV.

Também, do documento se pode concluir que, entre os conselheiros reais, havia uma séria inquietação e temor de que o progressivo avanço dos paulistas acabasse por atingir o Perú.

Com efeito, à certa altura, chamam a atenção de Sua Majestade para o fato de os bandeirantes terem chegado até a província de It $=l i m$, tão próxima de Santa Cruz de la Sierra (apenas $\mathbf{8 0}$ léguas) que, por sua vez, dista apenas outras 80 léguas de Potosí, ressaltando os perigos que daí poderiam provir. E acrescentam: "A Província do Paraguai está arruinada, pois de quatro cidades que tinha the faltam três, e só lhe fica a cidade de Assunção, cujos moradores apenas podem se defender dos ínđios guaicurús que, se se juntarem com os portuguêses que vão do Brasil, se apoderarão absolutamente de tudo, ficando em tão perigosa proximidade e grande risco o Perú...".

Destarte, embora as acusações jesuíticas contra as bandeiras fôssem um terrível libelo, os castigos e penas previstos para novas entradas fazem pensar que houve uma preocupação maior em criar uma barreira aos portuguêses em geral e aos paulistas em particular ao caminho em demanda ao Perú, do que pròpriamente de preservar as remanescentes reduçōes. $O$ revés sofrido pelos paulistas em M'Bororé no início do ano de 1641, já não seria fru- 
to dessa política? Não teria conseguido Montoya permissão e facilidades para armar os indígenas, menos pròpriamente pela sua salvação do que por serem êles como um "tampão" do caminho para o Perú?

Se atentarmos ainda a que, por essa época, se desencadeia em Lima a terrível perseguição contra os portuguêses "donos do comércio" daquela praça, podemos concluir que há uma unidade de ação contra os súditos portuguêses da corôa espanhola, em defesa dos privilégios do comércio peruano, que só vai terminar com a restauração de Portugal e consequiente ascensão de $D$. João IV ao trono português.

ASTROGILDO RODRIGUES DE MELLO Professor Catedrático de História da Civilização Americana da Faculdade de Filosofia, Ciências e Letras da Universidade de São Paulo. 